\title{
NASA picks Mars landing site
}

\section{Curiosity rover will explore Gale Crater, which may hold clues to past habitability.}

\section{BY ERIC HAND}

$\mathrm{C}$ uriosity had better strap on its climbing gear. NASA has decided that the US\$2.5-billion Mars rover - the most ambitious mission yet to the red planet - will land in Gale Crater, a 155-kilometre-wide bowl with a mountain at its centre.

The selection, announced on 22 July, ends a competitive five-year process that considered some 60 sites for the Mars Science Laboratory mission. In the quest to discover whether Mars could ever have supported life, Gale Crater has something for everybody - including a 5-kilometre-tall mountain of stacked sediments.

"This might be the tallest mountain in the Solar System that we can climb with a rover," says John Grotzinger, the mission's project scientist and a geologist at the California Institute of Technology in Pasadena.

Four sites, each supported by a vocal group of advocates, reached the shortlist. Gale offered the most to geomorphologists - geologists who study layers of sediment for clues to the processes that laid the layers down. But it also presented ample opportunities to geologists who probe the chemistry of minerals. "Gale is a geomorphologist's dream," says Phil Christensen, a Mars researcher at Arizona State University in Tempe. "But it has enough mineralogy to be interesting."

Curiosity will launch later this year. After a nine-month trip, the 900-kilogram rover, which will carry ten instruments and is built to travel 200 metres a day, will touch down within Gale. Initial plans include a visit to a fan-shaped deposit of sediments that seem to have spilled in through a breach in the crater rim, perhaps transported by water.

The rover will then set out for the mountain. The layered formation was laid down in the crater over several hundred million years, then partially eroded away. Orbiting satellites have spied evidence on the lower slopes of

\section{ONATURE.COM}

Take a virtual tour of Curiosity's landing site: go.nature.com/3uis7e

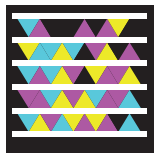

Scan the tag above with the free app from gettag.mobi thin layers of sulphates and clays - minerals formed in the presence of water. Determining the abundance and distribution of the minerals, and whether they were formed by groundwater, lake water or precipitation, will help researchers to learn about the habitability of ancient Mars. There are fewer

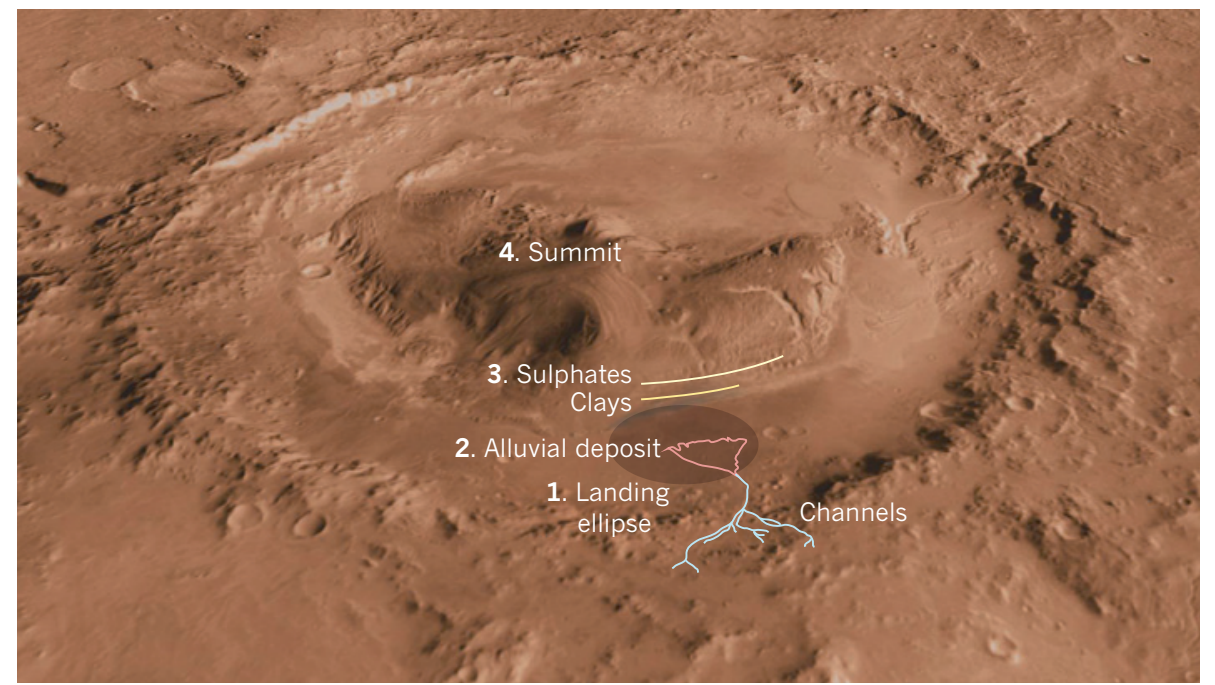

NASA's Curiosity rover will land (1) in Gale Crater. It will visit an expanse of sediment (2) deposited by channels, then climb a mound bearing water-related minerals (3). It may try to reach the summit (4).

signs of erosion and watery minerals farther up the mountain, but scientists will still want Curiosity to reach the summit. "If you started at the bottom of the Grand Canyon, you wouldn't stop a third of the way up," says Christensen. But the climb would take years longer than the mission's nominal two-year lifetime.

Grotzinger says that all three of the other finalist sites were promising. Eberswalde Crater, which was voted a close second, contains a relic of a river delta and might have offered the best chance of finding preserved organic molecules. Mawrth Vallis, the most ancient of the shortlisted sites, was favoured by French researchers who, using an instrument on the European Space Agency's Mars Express orbiter, found stronger signs of water-formed minerals in the

\section{LANDING SITES MATTER}

In 2003, NASA sent two rovers to Mars. Data from the landing sites produced markedly different amounts of published research.

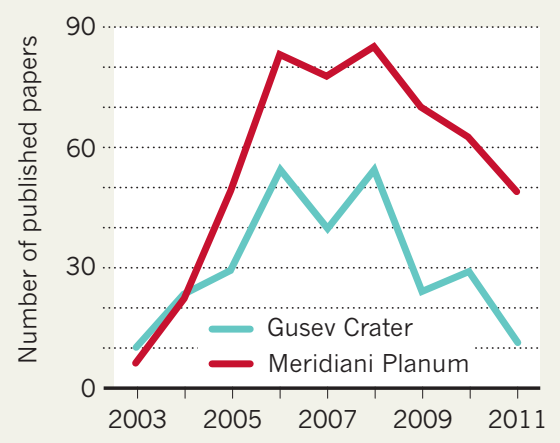

valley than anywhere else on the planet (F. Poulet et al. Nature 438, 623-627; 2005). Finally, Holden Crater, like Gale, may hold ancient lake deposits. "In the end," says Grotzinger, "we picked the one that felt best."

Engineers said that Curiosity could be landed safely at any of the four sites, so they left the final choice to the scientists. That placed the burden of choice on Grotzinger and his team something researchers did not face before the launch of NASA's Mars Exploration Rovers in 2003. Then, safety considerations ruled out all but two sites - and because there were two rovers, Spirit and Opportunity, both were selected. But the results of that mission demonstrate the importance of site selection (see 'Landing sites matter'). Opportunity's observations of Meridiani Planum - a plain rich in the mineral haematite - have produced far more scientific papers than Spirit's exploration of Gusev Crater. Scientists expected Gusev to hold lake deposits, but it turned out to be covered in comparatively boring volcanic basalt.

Gale Crater was considered for the 2003 rovers. Ultimately, NASA decided that it was too challenging to land a rover in Gale at the time, and the crater was too big for rovers that were expected to traverse only 600 metres over a lifetime of 3 months. But the Opportunity rover has exceeded expectations: it has now entered its seventh year on Mars, and travelled nearly 33 kilometres. If Curiosity has anything like its predecessor's endurance, the vast and intriguing Gale Crater will probably prove an ample playground for an extended mission. 